\title{
Local discrepancies in continental scale biomass maps: a case study over forested and non-forested landscapes in Maryland, USA
}

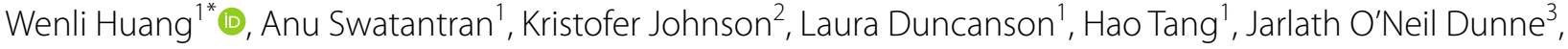
George Hurtt ${ }^{1}$ and Ralph Dubayah ${ }^{1}$

\begin{abstract}
Background: Continental-scale aboveground biomass maps are increasingly available, but their estimates vary widely, particularly at high resolution. A comprehensive understanding of map discrepancies is required to improve their effectiveness in carbon accounting and local decision-making. To this end, we compare four continental-scale maps with a recent high-resolution lidar-derived biomass map over Maryland, USA. We conduct detailed comparisons at pixel-, county-, and state-level.

Results: Spatial patterns of biomass are broadly consistent in all maps, but there are large differences at fine scales (RMSD 48.5-92.7 $\mathrm{Mg} \mathrm{ha}^{-1}$ ). Discrepancies reduce with aggregation and the agreement among products improves at the county level. However, continental scale maps exhibit residual negative biases in mean (33.0-54.6 Mg ha-1) and total biomass (3.5-5.8 Tg) when compared to the high-resolution lidar biomass map. Three of the four continental scale maps reach near-perfect agreement at $\sim 4 \mathrm{~km}$ and onward but do not converge with the high-resolution biomass map even at county scale. At the State level, these maps underestimate biomass by $30-80 \mathrm{Tg}$ in forested and 40-50 Tg in non-forested areas.

Conclusions: Local discrepancies in continental scale biomass maps are caused by factors including data inputs, modeling approaches, forest/non-forest definitions and time lags. There is a net underestimation over high biomass forests and non-forested areas that could impact carbon accounting at all levels. Local, high-resolution lidar-derived biomass maps provide a valuable bottom-up reference to improve the analysis and interpretation of large-scale maps produced in carbon monitoring systems.
\end{abstract}

Keywords: Temperate deciduous forest, Lidar, Aboveground biomass, Carbon

\section{Background}

Accurate maps of forest aboveground biomass are critical for reducing uncertainties in the carbon cycle and informing carbon management decisions [1-3]. While no method provides direct measurements of biomass over large scales, a combination of remotely sensed data and a well established field inventory is considered suitable for monitoring programs such as REDD+ $[4,5]$. Data inputs for biomass estimation have varied widely with tradeoffs between

\footnotetext{
*Correspondence: wlhuang@umd.edu

${ }^{1}$ Department of Geographical Sciences, University of Maryland, College Park, USA

Full list of author information is available at the end of the article
}

availability, cost and coverage. Accuracy of estimated biomass has also varied with the sensitivity of data to forest structure, spatial resolution, choice of statistical models, and the accuracy of field training data. Regardless, biomass estimates from different maps seem to agree at very coarse scales [4]. For example, Mitchard et al. [4] found that pantropical biomass maps converged at regional scales even though they varied locally. They concluded that uncertainties were largely related to spatial patterns of forest cover change. Langner et al. [5] evaluated pan-tropical biomass maps and successfully combined them into a framework for deriving REDD+ Tier 1 carbon storage estimates. While these findings are encouraging for national and 
continental scale reporting, there is a need to examine local discrepancies more closely as errors or uncertainty at fine-scales can complicate the use of coarse scale maps in local planning and decision making.

Almost all large-area biomass maps are derived from two-dimensional remote sensing data that have wide coverage but are generally less sensitive to canopy structure, particularly in moderate to high biomass forests (e.g. multispectral and single polarized SAR). Furthermore, they do not currently include fine scale variations in tree cover because of their coarse spatial resolution. Lidar instruments measure three-dimensional canopy structure which improves the accuracy of biomass maps [3] but lidar datasets have limited coverage and are expensive to acquire. An alternative is to use high-resolution lidar derived biomass maps, where available, to evaluate existing coarse scale maps, and make them more compatible for decision-making.

In 2010, NASA initiated the Carbon Monitoring System (CMS) to quantify carbon sources and sinks for an improved understanding of the global carbon cycle [6]. The program combines top-down continental scale approaches with bottom-up local scale approaches. The top-down approach relies on satellite observations to quantify carbon storage and terrestrial fluxes for national reporting. The bottom-up approach focusses on mapping carbon stocks and uncertainties at fine scales. Within the US, continental scale maps use Forest Inventory Analysis (FIA) plot data for model development, and biomass estimates are in turn compared with FIA county or regional averages as a type of validation [7-9]. However, these validations are not based on independent data, and often lack constraints at high spatial resolution. Moreover, field inventories generally do not include trees outside forests [9]. Continental scale maps therefore do not predict biomass outside forested areas and may significantly underestimate carbon balances [10].

A thorough understanding of local-scale discrepancies requires an independently derived high-resolution estimate. Recently, such a map was produced for the state of Maryland as part of CMS [11, 12]. Biomass estimates were derived from lidar data in conjunction with nonFIA field data using machine-learning approaches. The $30 \mathrm{~m}$ biomass maps incorporated tree canopy cover at the $1 \mathrm{~m}$ resolution, thus including forested and non-forested trees in the process. This local scale effort provides a reference for evaluating existing coarse scale maps.

We present results from a detailed comparison of the biomass map produced over Maryland (hereafter referred to as CMS_RF) with four national scale biomass maps: (A) NBCD2000 [13], (B) Blackard [14], (C) Wilson [15], and (D) Saatchi [16] at the pixel-, county- and state-level. We quantify the degree and spatial patterns of differences to gain an improved understanding of map discrepancies and their impacts on carbon accounting.

\section{Methods}

\section{Study area and field data}

Maryland has a land area of $\sim 25,600 \mathrm{~km}^{2}$ (Fig. 1) and can be divided into 3 major physiographic provinces (or ecoregions) based on species-composition and environmental gradients. These are the Eastern Coastal Plain (hereafter, "Eastern Shore"), the combined Western Coastal Plain and Piedmont (hereafter, "Piedmont") and the combined Blue Ridge, Valley and Central Appalachians (hereafter, "Appalachian"). The wide variability in topography, forest types, and environmental gradients makes it a suitable test-bed for national map comparisons.

We first generated a biomass map using existing lidar data and independent field estimates. Field data were collected in 848 variable and fixed radius plots selected through a stratified sampling of NLCD land cover (evergreen, deciduous, wetlands, mixed and non-forest) and lidar canopy heights (Fig. 1). Tree measurements of diameter at breast height $(\mathrm{dbh})$ and species were recorded in each plot. Allometric estimates of aboveground biomass $\left(\mathrm{Mg} \mathrm{ha}^{-1}\right)$ were calculated for each tree using equations from Jenkins et al. [17] and appropriate blow up factors were applied to estimate biomass density for the variable radius plots. For more details on field data collection, refer to $[11,18]$. In addition to these new plots, FIA data were obtained from across the state and used for model validation only [9].

\section{Local scale CMS_RF biomass map}

Leaf-off, discrete return lidar data were obtained from the Maryland Department of Natural Resources (DNR) and individual counties. Tree canopy cover and canopy height were mapped at $1 \mathrm{~m}$ resolution using a combination of Lidar and high-resolution leaf-on multispectral imagery for every county and seamlessly across the entire state $[19,20]$. Lidar canopy height models were masked using high-resolution tree cover to obtain canopy heights over forested and non-forested areas. Lidar metrics such as height percentiles, densities, and canopy cover were calculated within $30 \mathrm{~m}$ grid cells corresponding to the NLCD land cover dataset. Field based estimates of biomass were then related to the lidar metrics using Random Forests regression models [21, 22]. Three separate empirical models were developed, one for each physiographic region, and were applied to predict biomass for counties within the region. Predictions over individual counties were merged into a statewide biomass map at $30 \mathrm{~m}$ resolution (CMS_RF map). Details of the biomass estimation are available in [18] and [12]. 


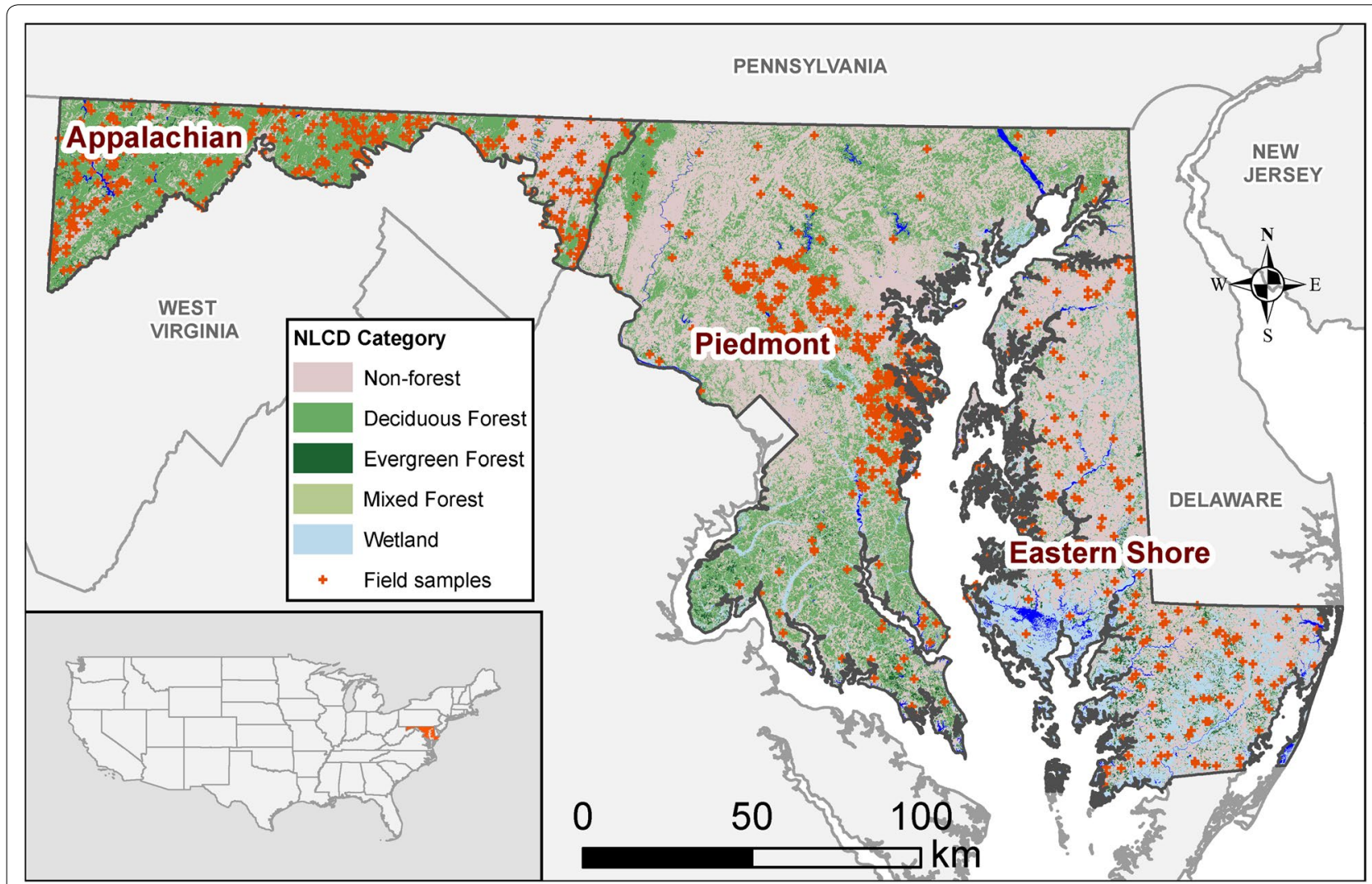

Fig. 1 Study area showing physiographic regions and field plot locations. Physiographic provinces (Appalachian, Piedmont, and Eastern Shore) are divided based on species-composition and environmental gradients. Land cover classes (Evergreen, Deciduous, Mixed, Wetlands, and Non-forest) are taken from the NLCD2006 database.

\section{Continental scale biomass maps}

Four national biomass products (Fig. 2; Table 1) were compared to the CMS_RF map. Each of these maps was derived using medium to coarse resolution satellite imagery. The NBCD2000 was the first $30 \mathrm{~m}$ national product developed using InSAR data from the 2000 Shutter Radar Topography Mission (STRM) and Landsat ETM+ data [13, 23]. NBCD2000 provided two versions of biomass: (A) NBCD_FIA map in which tree-level biomass estimates were obtained from tree tables in the FIA database (FIADB); and (B) NBCD_NCE or National Consistent allometric Equations in which biomass estimates were derived from equations developed by Jenkins et al. [17]. We used the NBCD_NCE version for consistency with our field biomass estimates, which were also derived from national allometric equations.

The Blackard map was developed at the $250 \mathrm{~m}$ spatial resolution [14] using tree-based regression (i.e., Cubist). It was developed by relating FIA plot data to multi-variable geospatial predictors, including Moderate Resolution Imaging Spectrometer (MODIS) data in 2001, percent tree cover and land cover proportions (from the NLCD
1992 product), topographical variables, and annual climate parameters, etc.

The Wilson map, also developed at the $250 \mathrm{~m}$ spatial resolution, was derived from MODIS imagery data from 2002 to 2008 and FIA field plots using a Phenological Gradient Nearest Neighbor (PGNN) imputation approach and canonical correspondence analysis (CCA) models $[15,24]$. The Wilson map is a newer and improved version of the Blackard map.

The Saatchi map is a CMS national-scale map derived using a combination of NASA remote sensing data, forest inventory and ancillary data (the same method as [25]). Waveforms from the Geoscience Laser Altimeter System (GLAS) lidar were used to derive Lorey's height, which was then related to FIA biomass. The GLAS shots with predicted biomass estimates were used as ground truth (i.e., biomass plot samples) and related to multiple remote sensing inputs, including MODIS, PALSAR, and Landsat imagery using Maximum Entropy (MaxEnt) models for predicting biomass at the continental scale. An updated version of the Saatchi map (Saatchi et al., personal communication) reported improvements such 


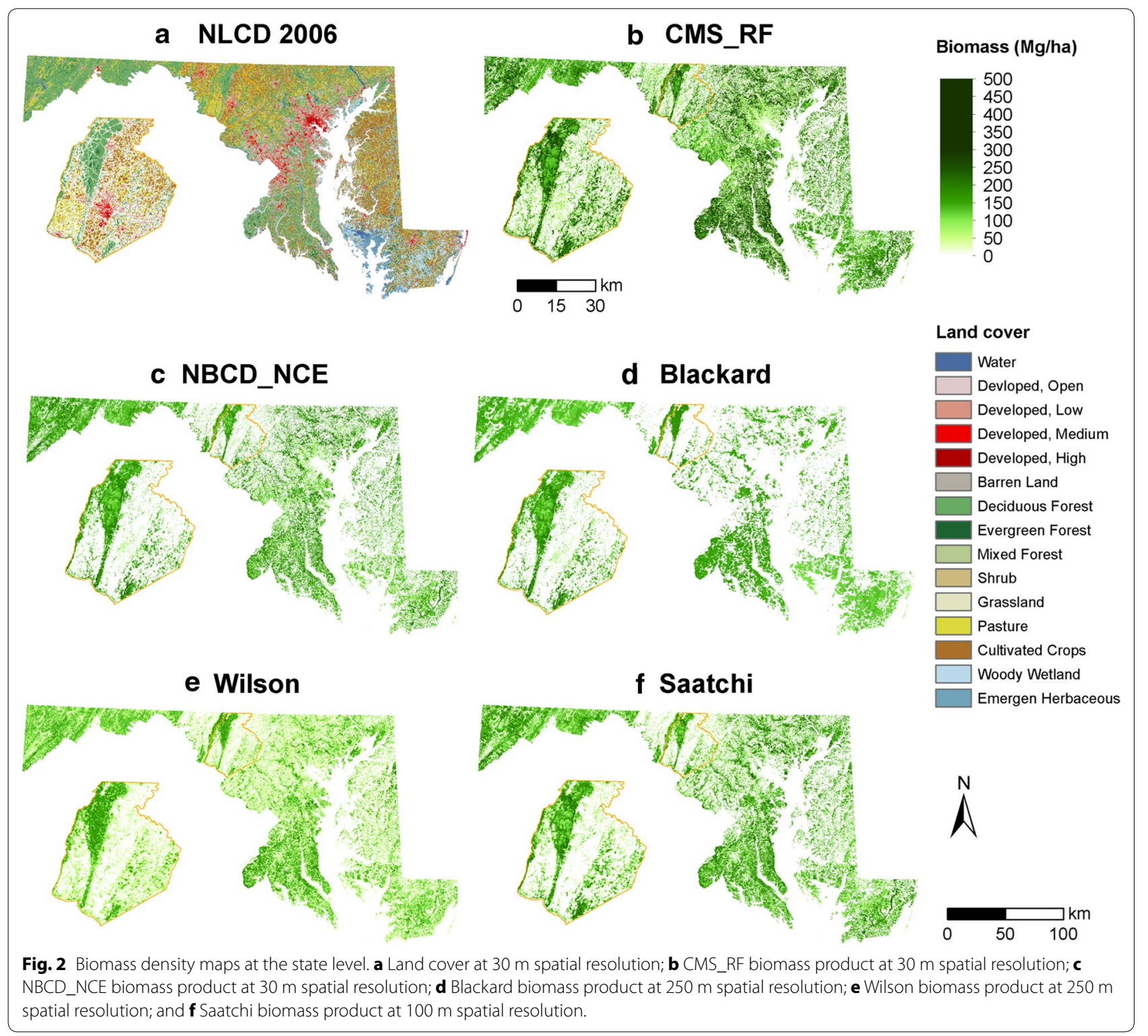

as: (A) reprocessed GLAS data, (B) 15 allometric equations that include three forest types (deciduous, coniferous, and mixed) for 5 regions of the US, and (C) NLCD non-vegetated gaps filled by PALSAR and Landsat data. We present results from the updated version but also include a comparison of the old and new versions in the supplement (Additional file 1: Figure S1 and Additional file 2: Figure S2).

\section{Map comparisons}

All maps were warped to a common frame of reference (UTM 18N NAD 83) ensuring minimum distortion to the native projections. Maps were matched to the same extents and pixel sizes. The $30 \mathrm{~m}$ biomass density maps (e.g. CMS_RF and NBCD_NCE) were aggregated to $250 \mathrm{~m}$ and coarser resolutions (e.g. $500 \mathrm{~m}, 1 \mathrm{~km}$, and $4 \mathrm{~km}$ ). The Wilson, Blackard (originally $250 \mathrm{~m}$ ), and Saatchi maps (originally $\sim 90 \mathrm{~m}$ ) were each aggregated to $500 \mathrm{~m}, 1 \mathrm{~km}$, and $4 \mathrm{~km}$.

A canopy cover mask was used to differentiate between forested and non-forested areas in our comparisons. The mask was created from the NLCD 2006 dataset for consistency with the land cover used in the CMS_RF stratification [18] and [12]. The mask included deciduous forest (41), evergreen forest (42), mixed forest (43), woody wetlands (90) and emergent herbaceous wetlands (95) from the NLCD dataset. NLCD defines forest as more than 20 percent of areas dominated by trees. Therefore, a $20 \%$ 
Table 1 Summary of biomass products used in this study

\begin{tabular}{|c|c|c|c|c|c|c|c|}
\hline Product & $\begin{array}{l}\text { Sensor } \\
\text { and year }\end{array}$ & $\begin{array}{l}\text { Field data } \\
\text { and year }\end{array}$ & Resolution & Forest mask & Approach & $\begin{array}{l}\text { Uncertainty } \\
\text { map }\end{array}$ & References \\
\hline CMS_RF & $\begin{array}{l}\text { DRL } \\
2004-2012\end{array}$ & $2011-2014$ & $30 m$ & $\begin{array}{c}\text { NAIP high-res tree } \\
\text { canopy cover }\end{array}$ & $\begin{array}{l}\text { Random forest, } \\
\text { regression tree }\end{array}$ & $\begin{array}{l}\text { Percentile error } \\
\text { (QRF) }\end{array}$ & {$[12,18]$} \\
\hline NBCD_NCE & $\begin{array}{l}\text { Landsat + SRTM } \\
2000\end{array}$ & 2000 & $30 m$ & NLCD 2001 & $\begin{array}{l}\text { Random forest, } \\
\text { regression tree }\end{array}$ & Quality voids & {$[13]$} \\
\hline Blackard & $\begin{array}{l}\text { MODIS } \\
2001^{a}\end{array}$ & 2005-2009 & $250 \mathrm{~m}$ & NLCD 1992 & $\begin{array}{l}\text { Cubist, regression } \\
\text { tree }\end{array}$ & Relative error & [14] \\
\hline Wilson & $\begin{array}{l}\text { MODIS } \\
2002-2008\end{array}$ & $2005-2009$ & $250 \mathrm{~m}$ & $\begin{array}{c}\text { NLCD } 2001 \text { percent } \\
\text { tree canopy } 25 \%\end{array}$ & PGNN, kNN & & {$[15]$} \\
\hline Saatchi & $\begin{array}{l}\text { MODIS + PAL- } \\
\text { SAR + Landsat }\end{array}$ & 2005 & $\begin{array}{l}\sim 250 \mathrm{~m} \mathrm{v} 1^{\mathrm{b}} \\
\sim 90 \mathrm{~m} \mathrm{v} 2^{\mathrm{b}}\end{array}$ & NLCD 2006 & $\begin{array}{l}\text { MaxEntropy, para- } \\
\text { metric }\end{array}$ & Percent error & {$[16]$} \\
\hline
\end{tabular}

a Year is national maps in eastern US.

b Original maps are in lat/lon, where v1 with $0.00222222 \cong 250 \mathrm{~m}$ and $\mathrm{v} 2$ with $0.00083333 \mathrm{deg} \cong 90 \mathrm{~m}$.

DRL Discrete Return Lidar, 1-2 m small footprint lidar aggregate, NAIP National Agriculture Imagery Program, QRF Quantile Regression Forests, SRTM Shuttle Radar Topography Mission, PALSAR Phased Array type L-band Synthetic Aperture Radar, PGNN Phenological Gradient Nearest Neighbor, kNN k-nearest neighbor.

threshold was set while aggregating the mask from 30 to $250 \mathrm{~m}$ and other coarse resolutions. Comparisons were made over: forested areas only; non-forested areas only; and over forested and non-forested areas combined.

Statistical indicators such as coefficient of determination $\left(\mathrm{R}^{2}\right)$, root mean squared difference (RMSD), RMSD\% or $\mathrm{CV}$ (coefficient of variation of the RMSD), and mean bias error (MBE) were used to compare the CMS_RF product with the four national maps. The Fuzzy Numerical Index (FNI) is a valuable quantitative descriptor of the spatial similarities and differences between maps and was included in our comparisons, following [26].

$$
\begin{aligned}
& R^{2}=1-\frac{\sum_{i=1}^{n}\left(C_{i}-M_{i}\right)^{2}}{\sum_{i=1}^{n}\left(M_{i}-\bar{M}\right)^{2}} \\
& R M S D=\sqrt{\sum_{i=1}^{n} \frac{\left(C_{i}-M_{i}\right)^{2}}{n}} \\
& R M S D \%=\frac{R M S D}{\bar{C}} \times 100 \\
& M B E=\frac{\sum_{i=1}^{n}\left(C_{i}-M_{i}\right)}{n} \\
& F N I=\frac{\sum_{i=1}^{n} 1-\frac{\left|C_{i}-M_{i}\right|}{\max \left(C_{i}, M_{i}\right)}}{n}
\end{aligned}
$$

$M_{i}$ is the value of national map; $C_{i}$ is the CMS_RF predicted value; $i$ is the sample index; $\bar{C}$ and $\bar{M}$ are the means of CMS_RF and national map respectively; and $n$ is the sample size.

\section{Results}

Spatial patterns of biomass were consistent with land cover and physiographic gradients in visual comparisons. Within forested areas, all maps showed distinct dendritic patterns corresponding to riparian zones that had higher biomass than surrounding areas. Similar spatial patterns of biomass were also noted along ridges, valleys and forested patches with high structural variability.

Although spatial patterns were similar, biomass densities and levels of detail varied considerably (Fig. 2). The CMS_RF biomass map provided greater detail over urban/suburban landscapes (Fig. 3, e.g. trees along roadsides, hedges and backyards) when compared visually with high-resolution [1 m] land cover map and highresolution imagery (Google Earth). The other maps predicted little or no biomass in non-forested areas. Differences over heterogeneous areas were particularly large (Fig. 3). Results ranged between 36,600 and 119,679 Mg, showing wide local-scale differences.

FNI provides a spatial representation of similarities and differences when calculated at a pixel-level. However, it does not capture the positive and negative deviations with respect to the CMS_RF map. We therefore calculated a mean FNI value for each map comparison with values ranging from 0 (perfect dissimilarity) to 1 (perfect similarity). A combination of map differences and FNI index values provided additional spatial and quantitative understanding of map discrepancies (Fig. 4; Table 2). Differences between maps were prominent in the Piedmont region, over counties in southern Maryland and along the Appalachians in the West. The Saatchi map was most similar to the CMS_RF map (FNI = 0.53) while the Blackard Map (FNI $=0.26)$ was the most dissimilar. The Wilson map had almost an equal proportion of similar 


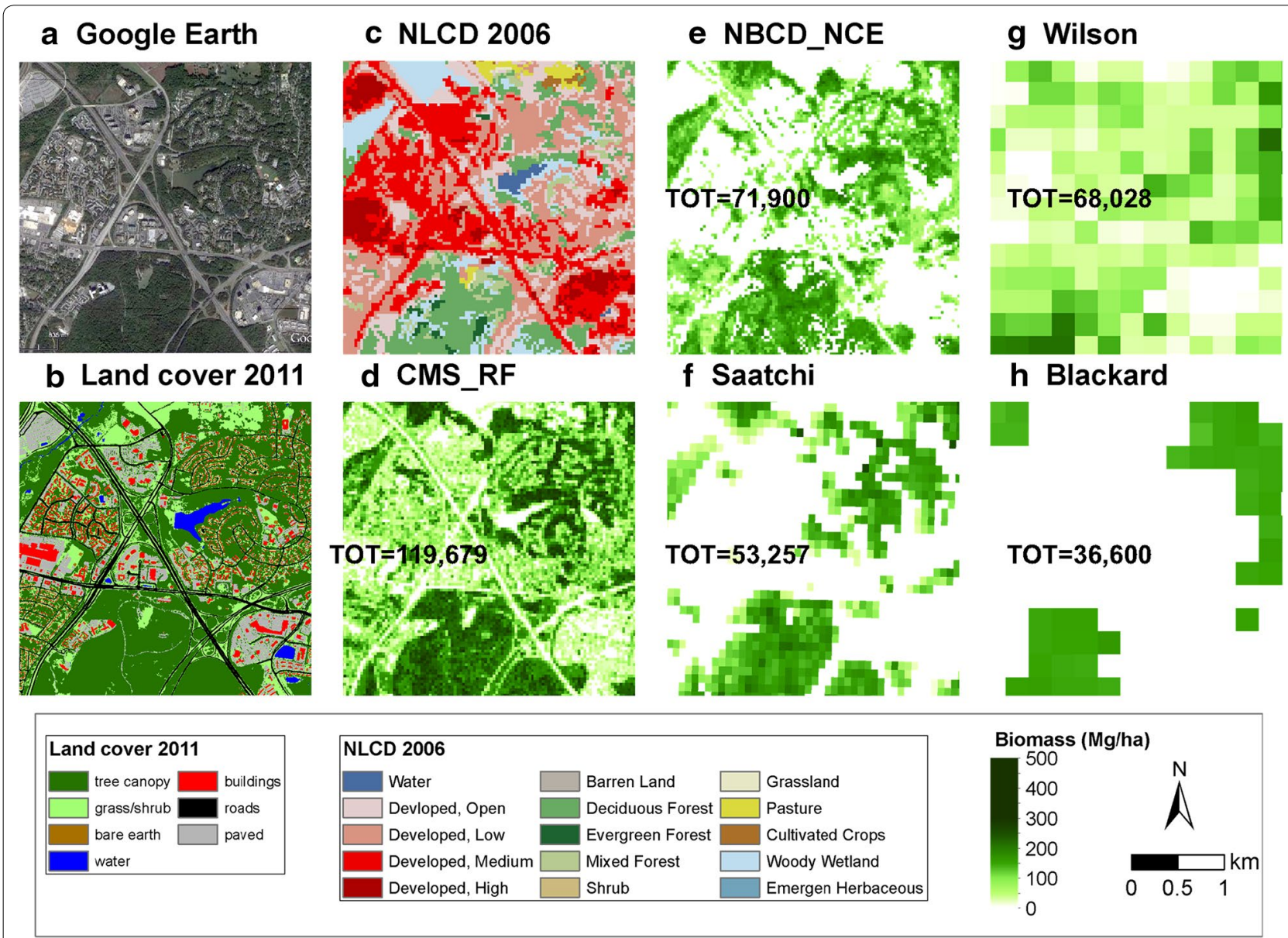

Fig. 3 Discrepancies in spatial distribution of biomass density at fine-scale. a Google Earth image in 2012; b high resolution [1 m] land cover map; c NLCD2006; d CMS_RF biomass product at $30 \mathrm{~m}$ spatial resolution; e NBCD_NCE biomass product at $30 \mathrm{~m}$ spatial resolution; f Saatchi biomass product at $100 \mathrm{~m}$ spatial resolution; $\mathbf{g}$ Wilson biomass product at $250 \mathrm{~m}$ spatial resolution; and $\mathbf{h}$ Blackard biomass product at $250 \mathrm{~m}$ spatial resolution. Zoom-in figures are for Frederick County.

and dissimilar pixels $(\mathrm{FNI}=0.49)$ while the NBCD map was slightly lower with an FNI of 0.48 .

\section{Comparisons at the pixel level}

(i) High-resolution comparisons [30 m]

Pixel level comparisons between the NBCD_ NCE and CMS_RF biomass products showed wide scatter with a large number of zero biomass predictions from the NBCD map (Fig. 5). Most areas that did not have biomass values on the NBCD map had predictions in the CMS_RF map. The NBCD biomass values were biased lower than the 1:1 line with an overall RMSD of $75.0 \mathrm{Mg} \mathrm{ha}{ }^{-1}$.Biomass distributions from CMS_RF and NBCD_NCE maps showed large differences over total and non-forested regions (Fig. 6). The NBCD_NCE distribution was bimodal with modes shifted toward the left (or lower biomass ranges). The CMS_RF map had higher and more widely distributed values over non-forested regions. The NBCD_NCE dataset did not predict biomass outside forests but the non-forest histograms had some high biomass values. This was because an older NLCD (2000) forest/non-forest mask was used to generate the NBCD_NCE map. The time lag between the maps and the difference in forest/non-forest masks complicated the comparisons but did not affect the overall trend in the forested and nonforested scatter plots (Fig. 5).

(ii) Comparisons with field data

We compared predictions from the CMS_RF and NBCD_NCE maps with biomass estimates from FIA data (average of four sub-plots) 

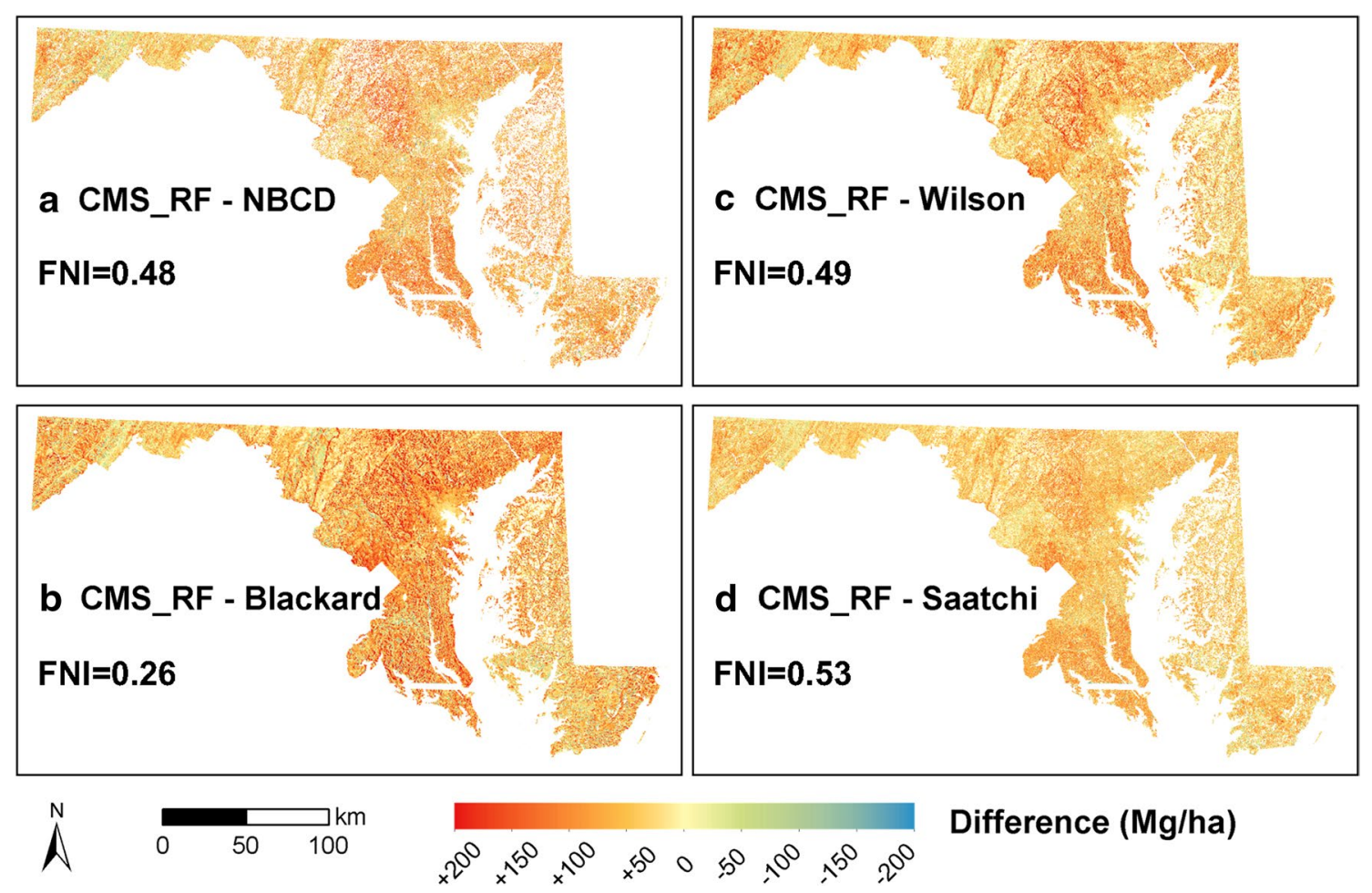

Difference (Mg/ha)

Fig. 4 Difference maps of biomass density. a CMS_RF-NBCD_NCE at $30 \mathrm{~m}$ spatial resolution; b CMS_RF-Blackard at $250 \mathrm{~m}$ spatial resolution; c CMS_RF-Wilson at $250 \mathrm{~m}$ spatial resolution; and d CMS_RF-Saatchi at $100 \mathrm{~m}$ spatial resolution. Areas in red have lower values and areas in blue have higher values than the CMS_RF map. Fuzzy Numerical Index (FNI) quantifies overall similarity between the national biomass maps and the CMS_RF map, ranging from 0 (fully distinct) to 1 (fully identical).

Table 2 Mean Fuzzy Numeric Index

\begin{tabular}{llll}
\hline Name & All & Forest & Non-forest \\
\hline NBCD_NCE & 0.48 & 0.62 & 0.22 \\
Blackard & 0.26 & 0.38 & 0.04 \\
Wilson & 0.49 & 0.52 & 0.41 \\
Saatchi & 0.53 & 0.69 & 0.25 \\
\hline
\end{tabular}

Values calculated from maps at $250 \mathrm{~m}$ resolution.

(Fig. 7a) and our variable radius field plots (Fig. 7b, c). The Random Forests model used to generate the CMS_RF map explained $~ 50 \%$ variability in biomass from variable radius field plots $\left(\mathrm{R}^{2}=0.49\right.$, RMSE $=89.3 \mathrm{Mg} \mathrm{ha}^{-1}$, $\mathrm{n}=848)$. A cross-validation of the CMS_RF map with plot level FIA data showed higher agreement, partly due to higher sample number $\left(\mathrm{R}^{2}=0.69\right.$, RMSE $\left.=58.2 \mathrm{Mg} \mathrm{ha}^{-1}, \mathrm{n}=1,055\right)$. On the other hand, a cross validation of the NBCD_NCE map with variable radius estimates resulted in substantially weaker relationships $\left(\mathrm{R}^{2}=0.14, \mathrm{RMSE}=125.1 \mathrm{Mg} \mathrm{ha}^{-1}, \mathrm{n}=433\right)$. (iii) Comparisons at the pixel level [250 m]

Large disagreements were observed in the scatter plots and associated errors at the $250 \mathrm{~m}$ resolution (Fig. 8). Overall RMSD values ranged between 48.5 and $92.7 \mathrm{Mg} \mathrm{ha}^{-1}$. The RMSD values ranged between 55.0 and $90.0 \mathrm{Mg} \mathrm{ha}^{-1}$ over forested regions, and between 33.9 and 103.9 $\mathrm{Mg} \mathrm{ha}^{-1}$ over non-forested regions. The Saatchi and NBCD maps agreed more closely with the CMS_RF map with fewer zero biomass values after spatial aggregation. The updated version of Saatchi map agreed closely with the NBCD and CMS_RF map, while the original version showed a large difference (Additional file 1: Figure S1 \& Additional file 2: Figure S2). The Blackard map was the least correlated with the CMS_RF map while the Wilson map had a large scatter around the 1:1 line.Histograms of biomass in intervals of $10 \mathrm{Mg} \mathrm{ha}{ }^{-1}$ were generated and analyzed over the entire range (0-400 $\left.\mathrm{Mg} \mathrm{ha}^{-1}\right)$ (Fig. 9). There was little agreement among the maps across the entire range of predicted values. The only similarities were between the NBCD_NCE and the Saatchi map 

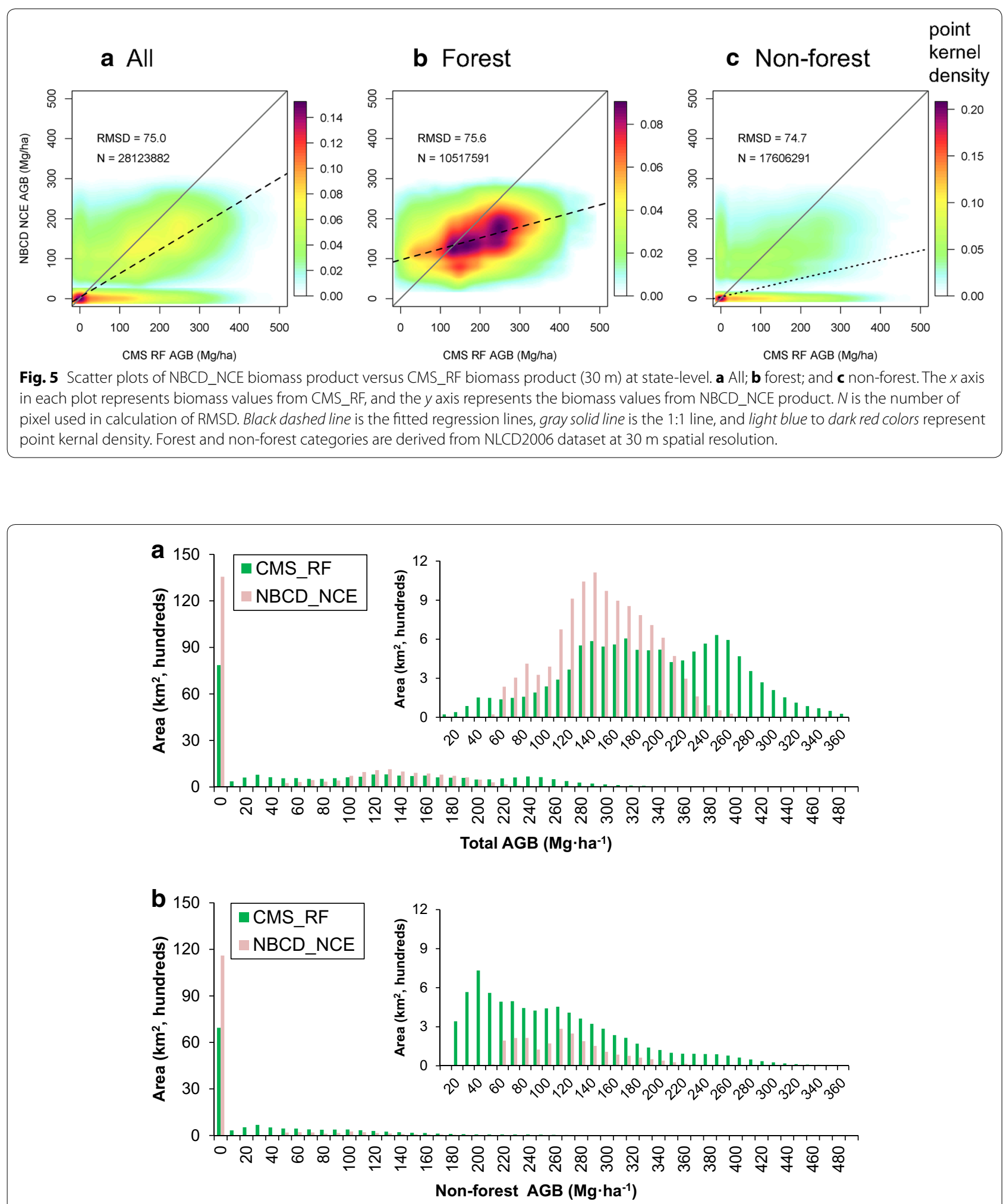

Fig. 6 Histograms showing the biomass distribution of CMS_RF and NBCD_NCE products over the state of Maryland at $30 \mathrm{~m}$ resolution in $10 \mathrm{Mg} \mathrm{ha}^{-1}$ bins. a All and $\mathbf{b}$ non-forest. Note that zero values are ignored in the inset plots. Non-forest category is derived from NLCD2006 dataset. 

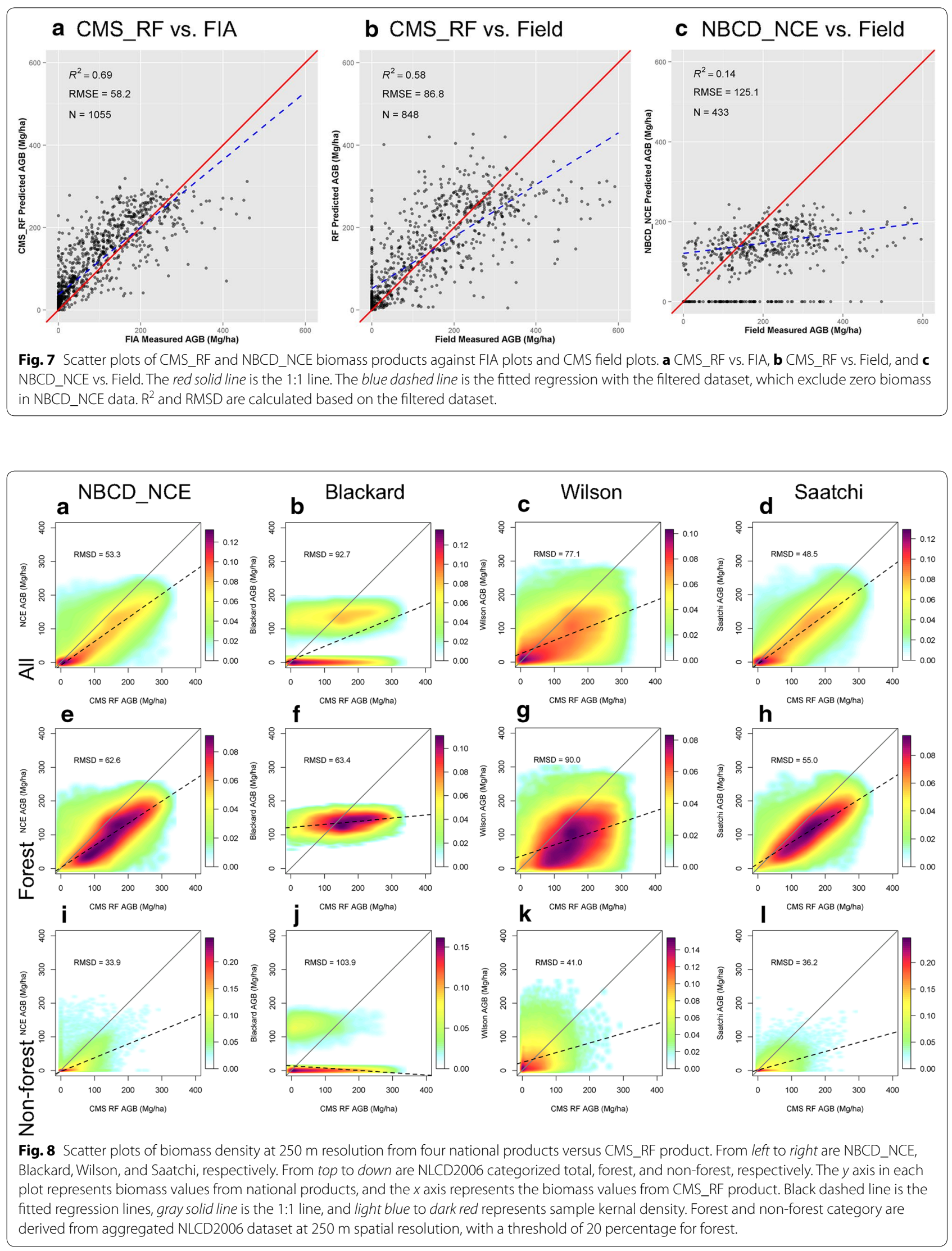

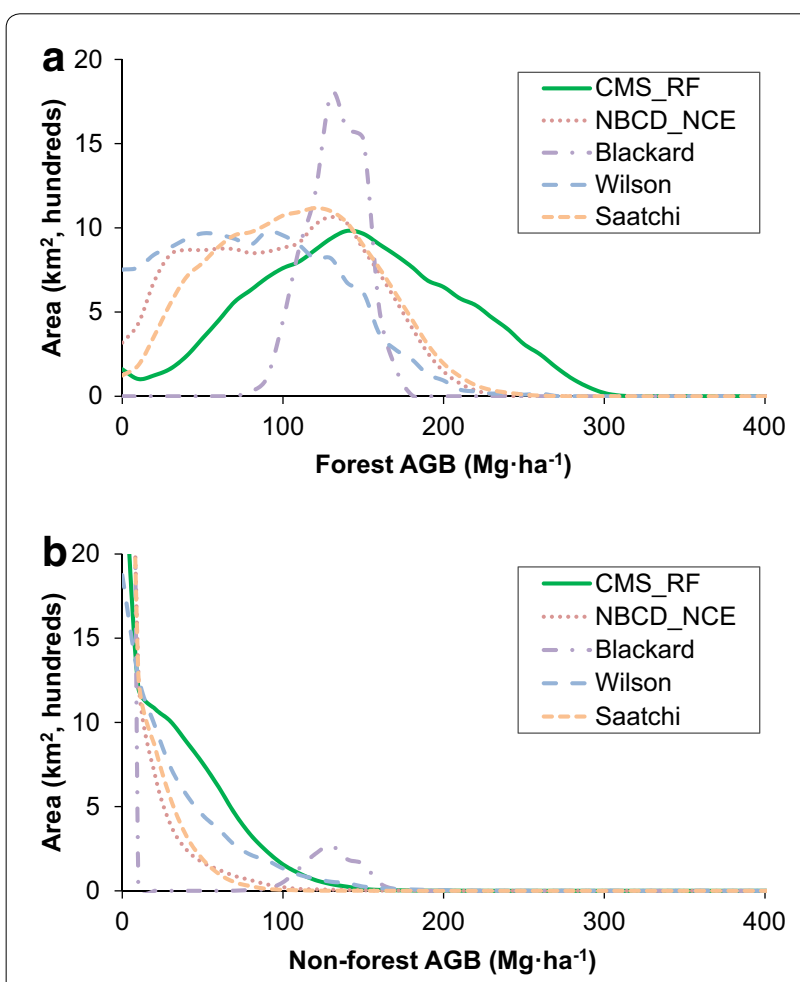

Fig. 9 Histograms showing the biomass density distributions of CMS_RF, NBCD_NCE, Blackard, Wilson, and Saatchi products over the state of Maryland at $250 \mathrm{~m}$ resolution in $10 \mathrm{Mg} \mathrm{ha}^{-1}$ bins. a Forest, and $\mathbf{b}$ non-forest.

above $125 \mathrm{Mg} \mathrm{ha}^{-1}$. The distribution of biomass in different ranges was also vastly different. Biomass values in the Blackard map were predominantly between 100 and $150 \mathrm{Mg} \mathrm{ha}^{-1}$ while all other datasets had values less than $250 \mathrm{Mg} \mathrm{ha}^{-1}$. Only the CMS_RF maps had predictions in ranges greater than $250 \mathrm{Mg} \mathrm{ha}^{-1}$.

\section{Comparisons at the county level}

At the county level, the four maps showed improved correlation with the CMS_RF map in both mean (Fig. 10) and total biomass (Fig. 11). Among the three physiographic regions, the counties in Appalachian region were closer to 1:1 line in all four products. Counties in Piedmont region had more evenly distributed biomass values in all products except the Blackard map. Counties in Eastern Shore region were more clustered, ranging between 40.1 and $79.2 \mathrm{Mg} \mathrm{ha}^{-1}$ for mean, and 4.6 and $7.8 \mathrm{Tg}$ for total biomass respectively. Despite the improved correlation, the MBE was high in all four products, ranging between -33.0 and $-54.6 \mathrm{Mg} \mathrm{ha}^{-1}$ for mean, and -3.5 and $-5.8 \mathrm{Tg}$ for total biomass respectively.

County totals from the continental scale maps and the CMS_RF map were also compared with FIA totals (Fig. 12). For this comparison, we used the gap-filled
Jenkins estimate from FIA data as it includes non-forested biomass [9]. Continental scale maps were strongly correlated with FIA at county level and had high coefficients of determination (0.63-0.80), but consistently underestimated biomass with a negative bias, ranging between -3.4 and $-1.1 \mathrm{Tg}$ for total biomass (Fig. 12a-d). The CMS_RF map showed good agreement too but had a positive bias and overestimated biomass, particularly in counties that had many low biomass areas such as in the Piedmont (Fig. 12e).

\section{Comparisons at the state level}

There were significant differences between the biomass totals at the state level (Fig. 13). The national maps estimated state totals between 126.0 and $170.6 \mathrm{Tg}$ and seemed to converge but were much lower when compared to the CMS_RF map. A detailed breakdown of mean and total biomass from all the maps is provided in Tables 3 and 4. The CMS_RF had higher mean (Tables 3, 4) and total biomass values (Fig. 13) over both forested and non-forested regions. The CMS_RF map also had higher total biomass than what is traditionally reported by FIA (164 Tg, 2008-2012 collection period) (Additional file 3: Table S1, [27]). However, we note that FIA does not measure trees in areas defined as "non-forest" and the allometric approach used by FIA to calculate tree biomass is known to give lower estimates in this region [9]. Adjusting for these nuances in the FIA data achieved better agreement with CMS_RF, although the FIA estimate was still lower by $43 \mathrm{Tg}$ (Additional file 3: Table S1, [28]).

Lastly, we examined the coefficient of determination and corresponding errors as a function of resolution to detect trends and convergence between the maps (Fig. 14). The $\mathrm{R}^{2}$ values for both total and mean biomass increased with decreasing resolution, gradually moving closer to 0.90 . Correspondingly, RMSD values decreased gradually stabilizing at $\sim 35 \mathrm{Mg} \mathrm{ha}^{-1}$. The NBCD_NCE, Saatchi, and Wilson maps converged with near perfect agreement at around $4 \mathrm{~km}$ and onward. The Blackard map showed similar trends but less convergence with other products. Despite the improved agreement, the maps did not converge with the CMS_RF map at any scale considered in this study.

\section{Discussion}

Spatial patterns of similarities and differences were consistent with land cover and physiographic gradients. Geographically, the greatest spatial discrepancies were in the Piedmont region. This is not unexpected, given the urban development and suburban sprawl in the region. Coarse scale maps did not capture the heterogeneity of urbansuburban landscapes as finely as the CMS_RF map, hence the difference (Fig. 3). Distinct spatial patterns of 


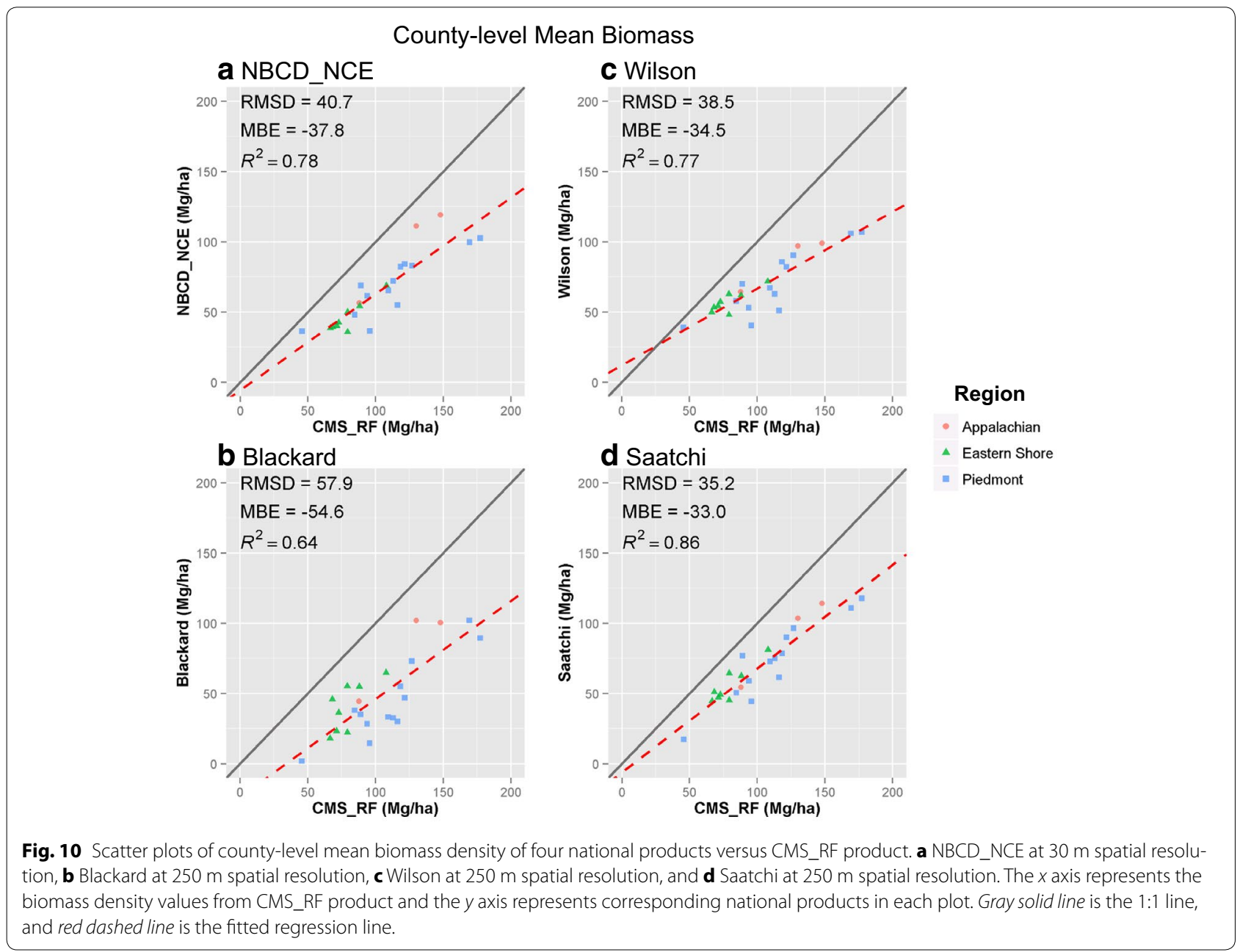

differences were also observed in Western Maryland and Southern Piedmont. These areas corresponded to dense forests where estimates from all the continental scale maps were lower. The Eastern shore had fewer discrepancies, probably because of sparse tree cover and lower biomass. However, unusually high values were noted in the national maps over several low-lying areas. This could be because of the mixed reflectance of water and vegetation over wetlands that is not easily separated in coarse resolution imagery [29].

We expected the $30 \mathrm{~m}$ NBCD_NCE map to be most similar to the CMS_RF map because it closely matched the spatial patterns in the CMS_RF map and had finer details than the other maps. However, the enhanced Saatchi map agreed more closely (Figs. 8, 4), despite having a coarse resolution $(\sim 90 \mathrm{~m})$ and fewer predictions beyond $250 \mathrm{Mg} \mathrm{ha}{ }^{-1}$. This was probably because the Saatchi map had more predictions in the $50-100 \mathrm{Mg} \mathrm{ha}^{-1}$ range than the NBCD_NCE map. The NBCD_NCE map had many pixels with very low biomass values (Fig. 9) which reduced its overall agreement with the CMS_RF map. Another surprising digression was the $250 \mathrm{~m}$ Wilson map that had a higher overall similarity index (FNI) than the NBCD_NCE map and the best agreement (Table 2) with the CMS_RF map over nonforested regions. A closer examination revealed that the Wilson map had better predictions in non-forested areas than any other map because it did not include a forest/ non-forest mask and was developed using different models for areas greater than and less than $50 \%$ NLCD forest cover. Thus, the agreement of continental scale maps with high-resolution estimates is not necessarily a function of spatial resolution but depends more on modeling approaches, time-lags and forest/non-forest definitions.

Choice of statistical/modelling approach was less critical in the CMS_RF estimation [18] but affected biomass predictions in other maps. The Blackard and Wilson maps used similar inputs yet had entirely different spatial distributions and histograms (Fig. 9) because of the difference in the regression models (Table 1). Similarly, 


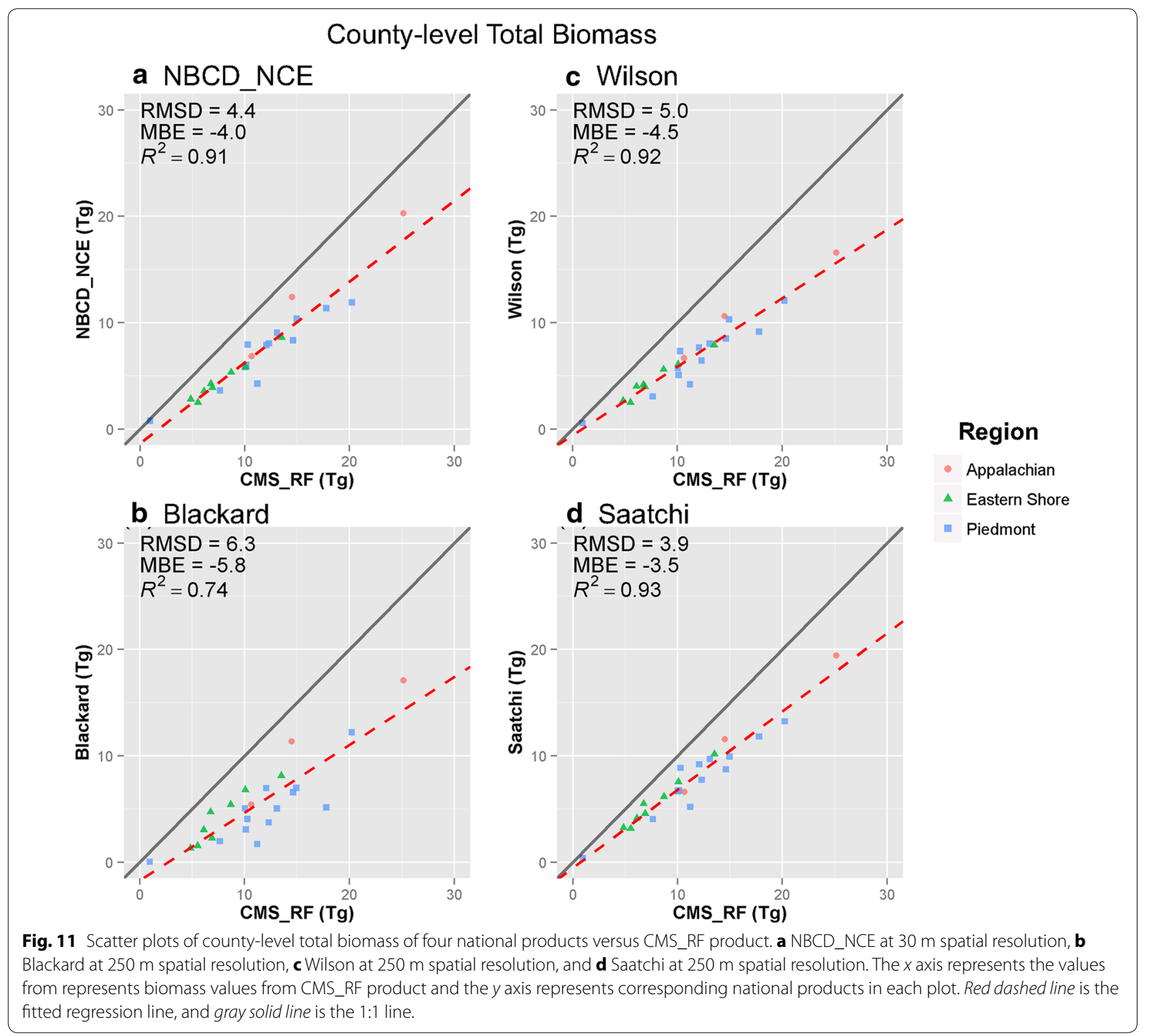

we noted a strong influence of the MaxEnt model in the form of stratified predictions (Additional file 1: Figure S1) from the original Saatchi map. Such discrepancies are not easily detected in a broad comparison but are evident in a pixel-by-pixel comparison, as demonstrated in this study.

Continental scale maps (except the Wilson map) did not predict values outside forested areas because of limited FIA field plots for model development. This reduced their total biomass estimates and increased pixel-level discrepancies with the CMS_RF map. While we acknowledge that a fair comparison cannot be made over nonforested regions, we quantified the effect of excluding non-forest biomass on county and state level totals. Our results indicate that the underestimation is non-trivial, particularly in heterogeneous landscapes such as our study area. We provide further corroboration to findings of [10] and support the need for including biomass outside forests in carbon reporting.

Some apparent non-forested biomass values crept into the national map totals (Fig. 13) because of time lags between maps and inconsistencies in forest/nonforest masks from the NLCD product. We noticed high values (greater than $100 \mathrm{Mg} \mathrm{ha}^{-1}$ ) in non-forest histograms from some national maps (Fig. 9). These could be artifacts of forested areas that were converted since the production of the maps or differences in NLCD classifications over time. Some non-forested biomass was a result of edge effects in the coarse scale maps. Discrepancies could also be attributed to canopy cover thresholds used for comparisons (e.g. $20 \%$ in this study). Larger 

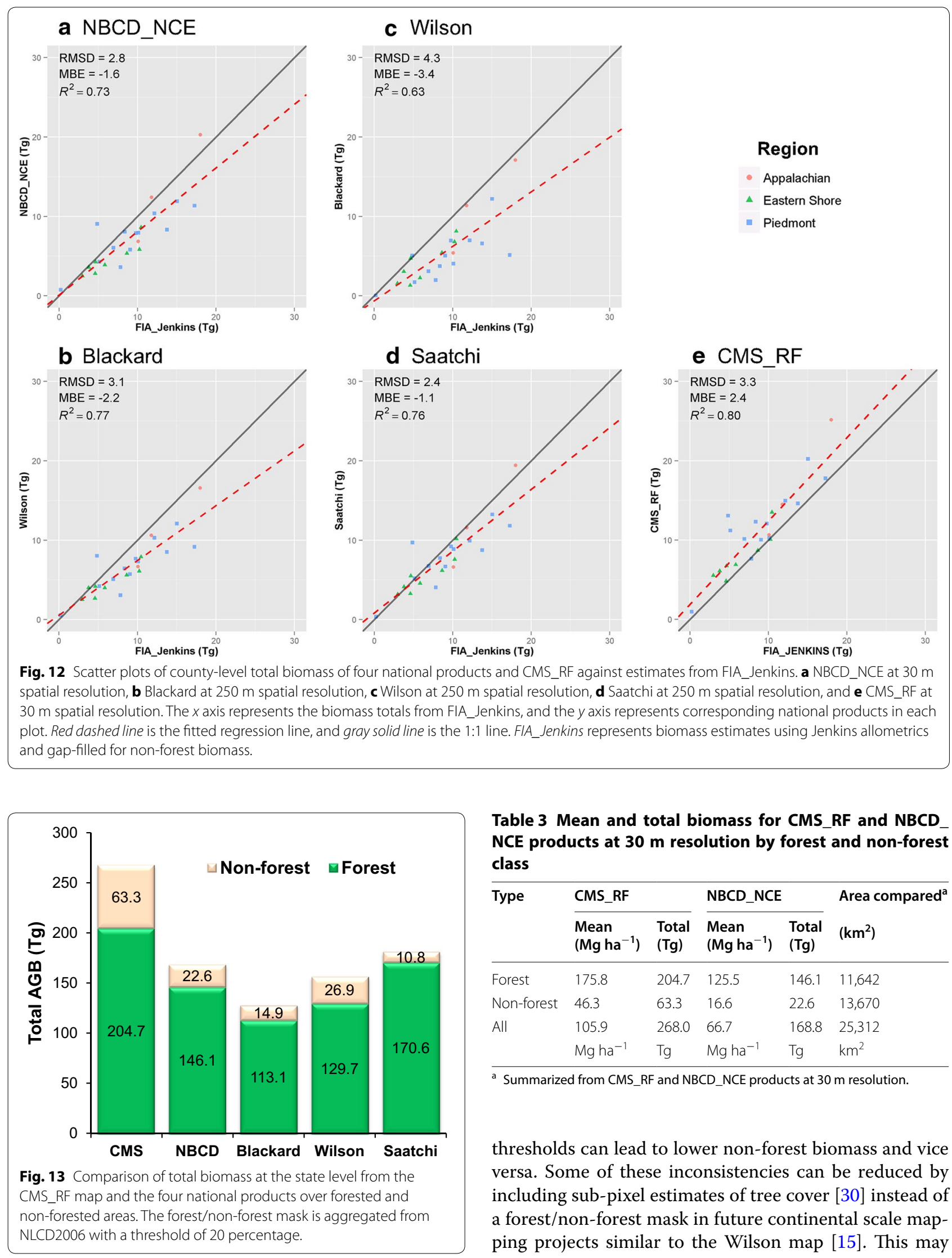

Table 3 Mean and total biomass for CMS_RF and NBCD_ NCE products at $30 \mathrm{~m}$ resolution by forest and non-forest class

\begin{tabular}{|c|c|c|c|c|c|}
\hline \multirow[t]{2}{*}{ Type } & \multicolumn{2}{|l|}{ CMS_RF } & \multicolumn{2}{|c|}{ NBCD_NCE } & \multirow{2}{*}{$\begin{array}{l}\text { Area compared } \\
\left(\mathrm{km}^{2}\right)\end{array}$} \\
\hline & $\begin{array}{l}\text { Mean } \\
\left(\mathrm{Mg} \mathrm{ha}^{-1}\right)\end{array}$ & $\begin{array}{l}\text { Total } \\
\text { (Tg) }\end{array}$ & $\begin{array}{l}\text { Mean } \\
\left(\mathrm{Mg} \mathrm{ha}^{-1}\right)\end{array}$ & $\begin{array}{l}\text { Total } \\
(\mathrm{Tg})\end{array}$ & \\
\hline Forest & 175.8 & 204.7 & 125.5 & 146.1 & 11,642 \\
\hline Non-forest & 46.3 & 63.3 & 16.6 & 22.6 & 13,670 \\
\hline \multirow[t]{2}{*}{ All } & 105.9 & 268.0 & 66.7 & 168.8 & 25,312 \\
\hline & $\mathrm{Mg} \mathrm{ha}^{-1}$ & $\mathrm{Tg}$ & $\mathrm{Mg} \mathrm{ha}^{-1}$ & $\operatorname{Tg}$ & $\mathrm{km}^{2}$ \\
\hline
\end{tabular}

a Summarized from CMS_RF and NBCD_NCE products at $30 \mathrm{~m}$ resolution.

thresholds can lead to lower non-forest biomass and vice versa. Some of these inconsistencies can be reduced by including sub-pixel estimates of tree cover [30] instead of a forest/non-forest mask in future continental scale mapping projects similar to the Wilson map [15]. This may 
Table 4 Mean and total biomass for three national products at $\mathbf{2 5 0} \mathrm{m}$ resolution by forest and non-forest class

\begin{tabular}{|c|c|c|c|c|c|c|c|}
\hline \multirow[t]{2}{*}{ Type } & \multicolumn{2}{|l|}{ Blackard } & \multicolumn{2}{|l|}{ Wilson } & \multicolumn{2}{|l|}{ Saatchi } & \multirow{2}{*}{$\begin{array}{l}\text { Area compared } \\
\left(\mathrm{km}^{2}\right)\end{array}$} \\
\hline & $\begin{array}{l}\text { Mean } \\
\left(\mathrm{Mg} \mathrm{ha}^{-1}\right)\end{array}$ & $\begin{array}{l}\text { Total } \\
\text { (Tg) }\end{array}$ & $\begin{array}{l}\text { Mean } \\
\left(\mathrm{Mg} \mathrm{ha}^{-1}\right)\end{array}$ & $\begin{array}{l}\text { Total } \\
(\mathrm{Tg})\end{array}$ & $\begin{array}{l}\text { Mean } \\
\left(\mathrm{Mg} \mathrm{ha}^{-1}\right)\end{array}$ & $\begin{array}{l}\text { Total } \\
\text { (Tg) }\end{array}$ & \\
\hline Forest & 97.2 & 113.1 & 111.4 & 129.7 & 146.6 & 170.6 & 11,642 \\
\hline Non-forest & 10.9 & 14.9 & 19.7 & 26.9 & 7.9 & 10.8 & 13,670 \\
\hline \multirow[t]{2}{*}{ All } & 50.6 & 128.0 & 61.9 & 156.6 & 71.7 & 181.5 & 25,312 \\
\hline & $\mathrm{Mg} \mathrm{ha}^{-1}$ & $\operatorname{Tg}$ & $\mathrm{Mg} \mathrm{ha}^{-1}$ & $\mathrm{Tg}$ & $\mathrm{Mg} \mathrm{ha}^{-1}$ & $\mathrm{Tg}$ & $\mathrm{km}^{2}$ \\
\hline
\end{tabular}

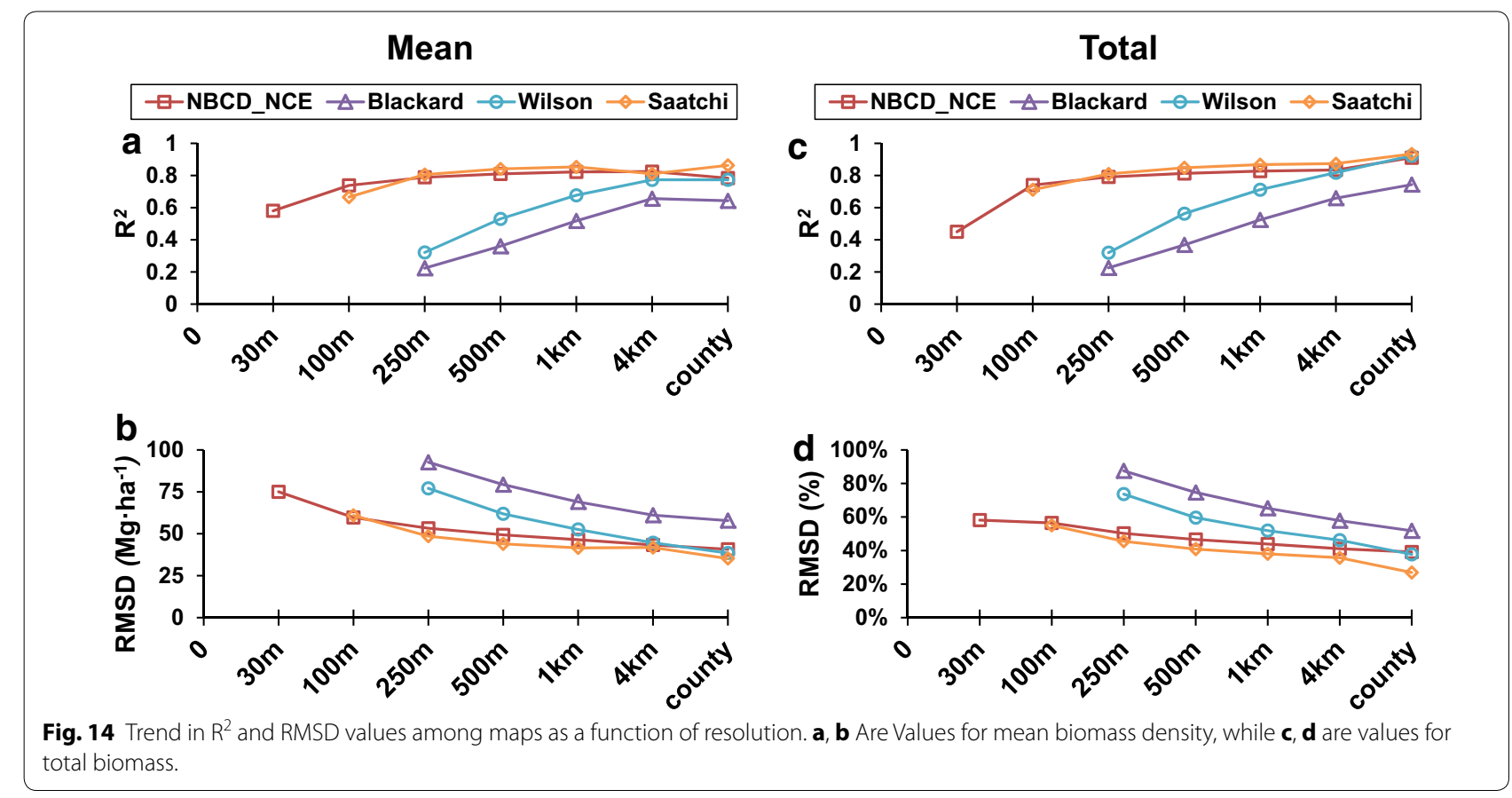

greatly improve the agreement among maps, particularly in the $0-250 \mathrm{Mg} \mathrm{ha}^{-1}$ range (Fig. 8).

Another important difference between the continental scale maps and CMS_RF map was in high biomass forests. Continental scale maps had few predictions greater than $250 \mathrm{Mg} \mathrm{ha}^{-1}$. This was because they were developed using passive multispectral/radar data that were not sensitive enough to canopy structure in medium to high biomass ranges [31]. We expected some improvement in the enhanced Saatchi map as it included space-borne lidar data but did not observe any. This was probably because lidar data were used for model calibration rather than prediction. Biomass predictions were therefore influenced more by the $2 \mathrm{D}$ remote sensing data than the lidar inputs. One way of improving estimates beyond the $250 \mathrm{Mg} \mathrm{ha}^{-1}$ range is by including lidar measurements with higher resolution such as those from GEDI (expected launch in 2018) [32] or ICESAT-2 (expected launch in 2017) as predictor variables individually or through fusion with other datasets.

Some discrepancy in total biomass values between the different maps can be attributed to the differences in allometric models applied to the field dataset used to develop the maps. For example, re-calculating tree biomass from field data in Maryland with Jenkins equations [17] instead of the Component Ratio Method (CRM) [33] that is currently used by FIA, increases the total biomass by $11 \%$. Therefore, it is possible that the difference between the CMS_RF map and the maps derived from field data that applied the CRM (i.e., Blackard, Wilson, and Saatchi), could be somewhat lower than calculated in Table 4.

In general, the CMS_RF map had higher values than all the other maps because the discrete-return airborne lidar were effective in predicting biomass beyond $250 \mathrm{Mg} \mathrm{ha}^{-1}$ and the high-resolution tree cover mask ensured estimates for virtually all trees in the State. We noted some 
overestimation, particularly in the low biomass ranges, when we compared the CMS_RF map to FIA county totals (Fig. 12). This could be attributed to the Random Forests model that predicted higher biomass in areas with very low canopy height and cover or limitations with FIA estimates. More research is needed to understand these differences but the cross-validation of the CMS_RF map with FIA data at plot level was strong (Fig. 7) indicating the overall robustness of the CMS_RF map and its suitability as a reference for map comparisons.

Interestingly, all maps showed better agreement at the county scale despite large discrepancies at finer scales. One reason for this could be that all maps captured some of the variability in biomass as a function of canopy structure, land cover type and physiographic gradient, irrespective of inputs and modeling approaches. This was evident from similarities in spatial patterns and FNI values. All maps (except the Blackard map) had greater than $45 \%$ similarity with the CMS_RF map at the pixel level, contributing to the agreement. Secondly, all continental scale maps were developed using statistical regressions with FIA data which is meant to provide an unbiased state-wide estimate. A regression model, by nature, estimates the mean of the predictor data. This is also applicable to the Random Forest model used to generate the CMS_RF map. Since all maps were more or less accurate in predicting mean biomass, there was a fundamental agreement despite the variability at fine scales. Outliers reduced on spatial aggregation and the agreement between maps increased, as observed from the decreasing RMSD and increasing goodness of fit (Fig. 14).

Continental scale maps showed increasing agreement at coarse scales and converged between $4 \mathrm{~km}$ and $10 \mathrm{~km}$ (county-scale). This is similar to trends observed in Mitchard et al. [4] and Avitabile et al. [26]. However, the agreement is misleading, as these maps do not converge with the CMS_RF map at any scale considered in this study (Fig. 14). The mismatch was because of a relatively constant negative bias in all the continental scale estimates when compared to the CMS_RF and was as high as $30 \%$ (Figs. 10,11) at county scale. The negative bias was primarily because of the underestimation in high biomass ranges and lack of predictions in non-forested areas. Since this difference does not diminish with coarsening resolution, we argue that local-scale discrepancies may affect carbon reporting at all levels and should not be ignored.

\section{Conclusion}

A detailed validation with high-resolution estimates can be valuable in identifying discrepancies and making continental-scale maps truly applicable to carbon accounting applications. We demonstrated one example over temperate forested and non-forested landscapes in Maryland. More studies across different biomes are required to confirm these findings. Armed with a comprehensive understanding from such validations, we can improve and integrate multi-source datasets to inform carbon monitoring efforts.

\section{Additional files}

Additional file 1: Figure S1. Scatter plots of biomass at $250 \mathrm{~m}$ resolution from old Saatchi (v1) and new Saatchi (v2) maps versus CMS_RF product.

Additional file 2: Figure S2. Histograms showing the distribution of forest biomass from old Saatchi (v1), new Saatchi (v2), and CMS_RF maps.

Additional file 3: Table S1. Total Maryland biomass, in Tg, for CMS_RF at $30 \mathrm{~m}$ resolution and FIA calculations (2008-2012 cycle) by forest and non-forest classification. FIA forest and non-forest definitions do not follow NLCD landcover classes, rather by on the ground plot conditions. Non-forest biomass in the FIA dataset was calculated by methods described in [28].

\section{Authors' contributions}

The study was designed by AS, WH and RD. WH performed the analysis and produced the figures using data layers and tables provided by KJ, LD, and HT. WH and AS wrote the manuscript and were co-first authors. All co-authors provided valuable feedback, interpretation of results and manuscript revisions. All authors read and approved the final manuscript.

\section{Author details}

${ }^{1}$ Department of Geographical Sciences, University of Maryland, College Park, USA. ${ }^{2}$ USDA Forest Service, Northern Research Station, Newtown Square, PA, USA. ${ }^{3}$ Rubenstein School of the Environment and Natural Resources, University of Vermont, Burlington, USA.

\section{Acknowledgements}

This work was funded by the NASA's CMS project (NNX10AT74G_PI, Ralph Dubayah). We are thankful to Sassan Saatchi for providing us the old and new versions of the CMS continental scale maps. We are thankful to Katelyn Dolan for her valuable inputs and comments that made the manuscript stronger. The datasets used in this study are available on line from: (a) CMS_RF [18] is available at http://carbonmonitoring.umd.edu/data.html, (b) NBCD [13] is available at http://www.whrc.org/mapping/nbcd/, (c) Blackard et al. [14] is available at http://webmap.ornl.gov/biomass/biomass.html, (d) Wilson et al. [15] at http:// www.fs.usda.gov/rds/archive/Product/RDS-2013-0004, (e) Saatchi et al. [16] is available at http://carbon.jpl.nasa.gov/data/dataMain.cfm.

\section{Compliance with ethical guidelines}

\section{Competing interests}

The authors declare that they have no competing interests.

Received: 15 June 2015 Accepted: 31 July 2015

Published online: 16 August 2015

\section{References}

1. Houghton R, Lawrence K, Hackler J, Brown S (2001) The spatial distribution of forest biomass in the Brazilian Amazon: a comparison of estimates. Glob Chang Biol 7(7):731-746

2. Lu D (2006) The potential and challenge of remote sensing-based biomass estimation. Int J Remote Sens 27(7):1297-1328

3. Goetz S, Dubayah R (2011) Advances in remote sensing technology and implications for measuring and monitoring forest carbon stocks and change. Carbon Manag 2(3):231-244 
4. Mitchard E, Saatchi S, Baccini A, Asner G, Goetz S, Harris N et al (2013) Uncertainty in the spatial distribution of tropical forest biomass: a comparison of pan-tropical maps. Carbon Balance Manag 8(1):10

5. Langner A, Achard F, Grassi G (2014) Can recent pan-tropical biomass maps be used to derive alternative Tier 1 values for reporting REDD+ activities under UNFCCC? Environ Res Lett 9(12). doi:10.1088/1748-9326/9/12/124008

6. Hurtt G, Wickland D, Jucks K, Bowman K, Brown M, Duren R et al (2014) NASA Carbon Monitoring System: prototype monitoring, reporting, and verification, 1-37

7. Zhang X, Kondragunta S (2006) Estimating forest biomass in the USA using generalized allometric models and MODIS land products. Geophys Res Lett 33(9). doi:10.1029/2006gl025879

8. Cartus O, Santoro M, Kellndorfer J (2012) Mapping forest aboveground biomass in the Northeastern United States with ALOS PALSAR dualpolarization L-band. Remote Sens Environ 124:466-478. doi:10.1016/j. rse.2012.05.029

9. Johnson K, Birdsey R, Finley A, Swantaran A, Dubayah R, Wayson C et al (2014) Integrating forest inventory and analysis data into a LIDAR-based carbon monitoring system. Carbon Balance Manag 9(1):3

10. Jenkins J, Riemann R (2003) What does nonforest land contribute to the global C balance? In: Proceedings of the 3rd annual forest inventory and analysis symposium. U.S. Department of Agriculture, Forest Service, North Central Station

11. Dubayah R, Swatantran A, Johnson K, Hurtt G, Zhao M, Finley A (2014) High resolution carbon estimation using remote sensing and ecosystem modeling in NASA's carbon modeling system. ForestSAT2014 open conference system

12. Swatantran A, Huang W, Duncanson L, Johnson K, Dunne JON, Hurtt G et al. High-resolution aboveground biomass mapping for carbon monitoring in Maryland (manuscript in preparation)

13. Kellndorfer J, Walker W, LaPoint E, Bishop J, Cormier T, Fiske G et al (2012) NACP aboveground biomass and carbon baseline data, V. 2 (NBCD 2000), U.S.A., 2000. Data set. Oak Ridge, Tennessee, U.S.A.: ORNL DAAC

14. Blackard J, Finco M, Helmer E, Holden G, Hoppus M, Jacobs D et al (2008) Mapping U.S. forest biomass using nationwide forest inventory data and moderate resolution information. Remote Sens Environ 112(4):16581677. doi:10.1016/j.rse.2007.08.021

15. Wilson BT, Woodall CW, Griffith DM (2013) Imputing forest carbon stock estimates from inventory plots to a nationally continuous coverage. Carbon Balance Manag 8(1):1. doi:10.1186/1750-0680-8-1

16. Saatchi S, Yifan Y, Fore A, Nuemann M, Chapman B, Nguyen et al (2005) CMS biomass pilot project: US Forest Biomass Maps

17. Jenkins JC, Chojnacky DC, Heath LS, Birdsey RA (2003) National-scale biomass estimators for United States tree species. For Sci 49(1):12-35

18. Dubayah R (2012) County-scale carbon estimation in NASA's carbon monitoring system. Biomass Carbon Storage

19. O'Neil-Dunne JPM, MacFaden SW, Royar AR, Pelletier KC (2013) An objectbased system for LiDAR data fusion and feature extraction. Geocarto Int 28(3):227-242. doi:10.1080/10106049.2012.689015

20. O'Neil-Dunne J, MacFaden S, Royar A, Reis M, Dubayah R, Swatantran A (2014) An object-based approach to statewide land cover mapping. Proceedings of ASPRS 2014 annual conference, 23-28 March 2014, Louisville, KY, USA
21. Breiman $L$ (2001) Random forests. Mach Learn 45(1):5-32

22. Cutler DR, Edwards TC Jr, Beard KH, Cutler A, Hess KT, Gibson J et al (2007) Random forests for classification in ecology. Ecology 88(11):2783-2792. doi:10.2307/27651436

23. Kellndorfer JM, Walker WS, LaPoint E, Kirsch K, Bishop J, Fiske G (2010) Statistical fusion of lidar, InSAR, and optical remote sensing data for forest stand height characterization: a regional-scale method based on LVIS, SRTM, Landsat ETM+, and ancillary data sets. J Geophys Res 115:G00E8. doi:10.1029/2009jg000997

24. Wilson BT, Lister AJ, Riemann RI (2012) A nearest-neighbor imputation approach to mapping tree species over large areas using forest inventory plots and moderate resolution raster data. For Ecol Manag 271:182-198. doi:10.1016/j.foreco.2012.02.002

25. Saatchi SS, Harris NL, Brown S, Lefsky M, Mitchard ETA, Salas W et al (2011) Benchmark map of forest carbon stocks in tropical regions across three continents. Proc Natl Acad Sci 108(24):9899-9904. doi:10.1073/ pnas.1019576108

26. Avitabile V, Herold M, Henry M, Schmullius C (2011) Mapping biomass with remote sensing: a comparison of methods for the case study of Uganda. Carbon Balance Manag 6(1):7

27. Miles P (2014) Forest Inventory EVALIDator web-application version 1.5.1.06. In: http://apps.fs.fed.us/Evalidator/evalidator.jsp. U.S. Department of Agriculture, Forest Service, Northern Research Station, St. Paul, MN

28. Johnson K, Birdsey RA, Cole J, Swantaran A, O'Neil-Dunne J, Dubayah R et al. Integrating LiDAR and forest inventories to fill the trees outside forests data gap. Environ Monit Assess (in review)

29. Adam E, Mutanga O, Rugege D (2010) Multispectral and hyperspectral remote sensing for identification and mapping of wetland vegetation: a review. Wetl Ecol Manag 18(3):281-296

30. Sexton JO, Song X-P, Feng M, Noojipady P, Anand A, Huang C et al (2013) Global, 30-m resolution continuous fields of tree cover: landsat-based rescaling of MODIS vegetation continuous fields with lidar-based estimates of error. Int J Digit Earth 6(5):427-448

31. Lu D, Chen Q, Wang G, Liu L, Li G, Moran E (2014) A survey of remote sensing-based aboveground biomass estimation methods in forest ecosystems. Int J Digit Earth 1-64. doi:10.1080/17538947.2014.990526

32. Dubayah R, Goetz S, Blair JB, Luthcke S, Healey S, Hansen M et al (2014) The Global Ecosystem Dynamics Investigation (GEDI) Lidar. ForestSAT2014 open conference system

33. Heath $L$, Hansen M, Smith J, Miles P, Smith W (2008) Investigation into calculating tree biomass and carbon in the FIADB using a biomass expansion factor approach. In: McWilliams W, Moisen G, Czaplewski R (eds) Proceedings of Forest Inventory and Analysis Symposium 2008. USDA Forest Service, Rocky Mountain Research Station, Fort Collins, Colorado, USA; Park City, Utah

\section{Submit your manuscript to a SpringerOpen ${ }^{\circ}$ journal and benefit from:}

- Convenient online submission

- Rigorous peer review

- Immediate publication on acceptance

- Open access: articles freely available online

- High visibility within the field

- Retaining the copyright to your article

Submit your next manuscript at $>$ springeropen.com 